\title{
The Crucial Role of Chromogranins in Storage and Exocytosis Revealed Using Chromaffin Cells from Chromogranin A Null Mouse
}

\author{
Monica S. Montesinos, ${ }^{1 *}$ J. David Machado, ${ }^{1 *}$ Marcial Camacho, ${ }^{1 *}$ Jesica Diaz, ${ }^{1}$ Yezer G. Morales, ${ }^{1}$ \\ Diego Alvarez de la Rosa, ${ }^{1}$ Emilia Carmona, ${ }^{2}$ Agustin Castañeyra, ${ }^{2}$ O. Humberto Viveros, ${ }^{1}$ Daniel T. 0'Connor, ${ }^{3}$ \\ Sushil K. Mahata, ${ }^{3}$ and Ricardo Borges ${ }^{1}$ \\ ${ }^{1}$ Unit of Pharmacology and ${ }^{2}$ Department of Anatomy, Medical School, University of La Laguna, 38071 Tenerife, Spain, and ${ }^{3}$ Hypertension Research Unit \\ 0838, University of California, San Diego, California 92161
}

\begin{abstract}
Chromogranins (Cgs) are the major soluble proteins of dense-core secretory vesicles. Chromaffin cells from Chga null mice [chromogranin A knock-out (CgA-KO)] exhibited $\sim 30 \%$ reduction in the content and in the release of catecholamines compared with wild type. This was because of a lower secretion per single exocytotic event, rather than to a lower frequency of exocytotic events. Cell incubation with L-DOPA produced an increase in the vesicular amine content of wild-type, but not CgA-KO vesicles. In contrast, intracellular electrochemistry showed that L-DOPA produced a significantly larger increase in cytosolic amines in CgA-KO cells than in the wild type. These data indicate that the mechanisms for vesicular accumulation in $\mathrm{CgA}-\mathrm{KO}$ cells were fully saturated. Patch-amperometry recordings showed a delayed initiation of the amperometric signal after vesicle fusion, whereas no changes were observed in vesicle size or fusion pore kinetics despite the smaller amine content. We conclude that intravesicular proteins are highly efficient systems directly implicated in transmitter accumulation and in the control of neurosecretion.
\end{abstract}

Key words: amperometry; catecholamines; fusion pore; neurosecretion; patch amperometry; secretory vesicle

\section{Introduction}

Chromogranins (Cgs) are acidic proteins consisting of single polypeptide chains that are mainly located within secretory vesicles such as chromaffin granules and large dense core vesicles of monoaminergic neurons (Taupenot et al., 2003). In these organelles, Cgs constitute the main protein component of the intravesicular matrix. Several functions have been proposed for Cgs including a granulogenic action (Mahapatra et al., 2005; Courel et al., 2006), sorting of secretory proteins into the regulated pathway (Gleave et al., 2001), $\mathrm{Ca}^{2+}$ and catecholamine (CA) sequestration (Helle et al., 1985; Videen et al., 1992; Wen et al., 2004), and as a source of bioactive peptides (Winkler et al., 1998; Taupenot et al., 2003). The presence of Cgs-derived active peptides has been linked to the regulation of arterial blood pressure (Ma-

Received Nov. 29, 2007; revised Jan. 15, 2008; accepted Feb. 7, 2008.

This work was supported by grants from the Spanish Ministerio de Educación y Ciencia (MEC) (BFU2004-08038) Gobierno de Canarias (PI042005/048), the National Institutes of Health, and the U.S. Department of Veterans Affairs. J.D.M. is the recipient of a "Juan de la Cierva" contract. M.C., M.S.M., Y.G.M., and J.D. are recipients of scholarships from the MEC. D.A.d.I.R. is the recipient of a "Ramón y Cajal" contract. O.H.V. is the recipient of a fellowship from the MEC and the University of La Laguna (ULL). We are grateful to Drs. Lindau, Álvarez de Toledo, Alés, Dernick, and Gómez for their help in the implementation of patch amperometry. We also thank Drs. Metz-Boutigue and FischerColbrie for their kind donations of $\mathrm{CgB}$ and Sgll antibodies. We are indebted to Dr. M. R. Arnau and C. Jiménez from the ULL Animal Care Facilities for their help with the maintenance of mouse strains. The help received from A. Jiménez (Hospital Universitario de Canarias) for the statistical analysis is greatly appreciated.

${ }^{*}$ M.S.M., J.D.M., and M.C. contributed equally to this work.

Correspondence should be addressed to Dr. Ricardo Borges, Pharmacology Unit, Medical School, University of La Laguna, 38071 La Laguna, Tenerife, Spain. E-mail: rborges@ull.es.

DOI:10.1523/JNEUROSCI.5292-07.2008

Copyright $\odot 2008$ Society for Neuroscience $\quad$ 0270-6474/08/283350-09\$15.00/0 hapatra et al., 2005) or innate immunity (Brekke et al., 2000). Finally, common genetic variation at the Chga locus confers heritable changes in expression and secretion of chromogranin A (CgA) and its derived peptides (Wen et al., 2004).

Amperometric measurements with microelectrodes in single chromaffin cells suggest that the discharge of vesicular CA after exocytosis is several orders of magnitude slower than predicted by the diffusion constant of CA in aqueous media (Schroeder et al., 1996). These authors attributed this slower diffusion rate to the presence of a granule matrix that binds CA, as was proposed previously (Helle et al., 1985). This role was also proposed for mast cells granule matrix where changes in ionic composition of the surrounding media, $\mathrm{pH}$, or electric potential produced changes in the association of soluble monoamines with the heparan sulfate matrix (Fernandez et al., 1991; Nanavati and Fernandez, 1993).

Previously, strains of mice with homozygous (-/-) targeted ablation [knock out (KO)] of the CgA locus have been developed (CgA-KO) (Mahapatra et al., 2005; Hendy et al., 2006). In this report, we used CgA-KO animals in combination with amperometry, patch amperometry, and intracellular electrochemical techniques to directly study, for the first time, the participation of intravesicular $\mathrm{CgA}$ in the storage and in the release process of CA from adrenal chromaffin cells.

\section{Materials and Methods}

Materials. Culture plates, sera, and culture media were from Nunc (Rochester, NY); papain was purchased from Worthington (Lakewood, 
NJ). All drugs were purchased from Sigma-Aldrich (Madrid, Spain). All salts used for buffer preparation were reagent grade.

Chromogranin A KO mice. All animal procedures were performed in agreement with institutional and national guidelines and regulations. The method to generate CgA-KO and their corresponding wild-type (WT) mice, as well as their overall phenotype has been described (Mahapatra et al., 2005). Briefly, a C57BL/6J mouse strain blastocyst was chosen for implantation of successfully targeted embryonic stem (ES) cells with a completely inactivated Chga allele. ES cells came from mouse strain CJ7, derived from 129/Sv mice. After suitable germ-line tests for transmission of the targeted transgene (backcrossing to the wild-type strain C57BL/6J), heterozygotes (Chga ${ }^{+/-}$; background strain 129/Sv) were mated to yield $\mathrm{F}_{1}$ generation. $\mathrm{F}_{1}$ generation animals were later inbred for seven generations to establish $\mathrm{Chga}^{-/-}$mouse line. Chga ${ }^{+/+}$ mouse line parents were $\mathrm{Chga}^{-/-}$littermates and, therefore, they were siblings with identical genomes. The WT $\left(\mathrm{Chga}^{+/+}\right)$mouse and KO mouse $\left(\mathrm{Chga}^{-1-}\right)$ used, are descended from these two homogeneous mouse lines generated by systematic inbreeding. One-month-old mice were genotyped by PCR using genomic DNA extracted from tail snips. The absence of CgA protein expression in the adrenal medulla was confirmed by immunoblot and immunocytochemistry.

Culture of mouse chromaffin cells. Cells were isolated from adrenal glands of one-month-old mice and cultured following the method of Sorensen et al. (2003) with minimal modifications. Tissues from mice younger than 1 month are easily digested with papain yielding large number of healthy chromaffin cells. Briefly, adrenal glands were dissected, placed in sterile Locke's buffer with the following composition (in mM): $154 \mathrm{NaCl}, 5.6 \mathrm{KCl}, 3.6 \mathrm{NaHPO}_{4}, 5 \mathrm{HEPES}$, and 5.6 glucose, adjusted to $\mathrm{pH}$ 7.3. The medullary tissue was isolated from the adrenal cortex under a surgical microscope. The medullae were incubated in 0.2 $\mathrm{ml}$ of Locke's buffer containing $16 \mathrm{IU}$ of papain at $37^{\circ} \mathrm{C}$ for $15 \mathrm{~min}$ without shaking. The enzyme solution was removed and replaced by fresh DMEM supplemented with $10 \%$ fetal calf serum, $50 \mathrm{IU} / \mathrm{ml}$ penicillin and $40 \mu \mathrm{g} / \mathrm{ml}$ gentamicin. The medullae were triturated gently by several passes through the fire-polished tip of a Pasteur pipette. The cell suspension was plated at an approximate density of $5 \times 10^{4}$ cells on 12-mm-diameter poly-D-lysine-coated coverslips. Cells were allowed to settle for $20 \mathrm{~min}$ at $37^{\circ} \mathrm{C}$, then $1 \mathrm{ml}$ of DMEM per well was added. Cells were maintained at $37^{\circ} \mathrm{C}$ and $5 \% \mathrm{CO}_{2}$ and used at room temperature between 0 and $3 \mathrm{~d}$ of culture.

Immunoblots. Adrenal medullae were removed and solubilized by homogenization in "TENT 1\%" containing (in mM) 50 Tris- $\mathrm{HCl}, \mathrm{pH} 7.4,5$ EDTA, $150 \mathrm{NaCl}$, and $1 \%$ Triton X-100, supplemented with a protease inhibitor cocktail (Complete; Roche Diagnostics, Mannheim, Germany). After determination of protein concentrations, equal amounts of each protein extract were separated on 10\% SDS-polyacrylamide gels. Proteins were then blotted onto polyvinylidene difluoride membranes (Immobilon-P; Millipore, Madrid, Spain) using a standard procedure.

The following primary antibodies and dilutions were used: rabbit polyclonal raised against an epitope corresponding to amino acids 158457 mapping at the $\mathrm{C}$ terminus of $\mathrm{CgA}$ of human origin (Santa Cruz Biotechnology, Santa Cruz, CA; catalog \#sc13090;) at 1:4000; rabbit polyclonal antiserum raised against bovine chromogranin B (CgB; amino acids 55-68), a kind gift from Dr. M. H. Metz-Boutigue (Inserm Unite 575, Strasbourg, France) at 1:4000; anti-secretogranin II (SgII) polyclonal antibody (against mouse secretoneurin fragment), a kind gift from Dr. R. Fischer-Colbrie (Innsbruck University, Austria), at 1:3000 dilution; and a mouse monoclonal anti-tyrosine hydroxylase (TH; Sigma, catalog \#T2928) at 1:8000. After incubation with secondary antibodies (anti-rabbit/anti-mouse horseradish peroxidase-conjugated IgG; $1: 10000$ ), the signal was developed with the ECL + system (GE Healthcare Bio-Sciences, Piscataway, NJ). Chemiluminescence signals were detected by an imaging system (Gel Logic 440; Kodak, Rochester, NY) and analyzed using the software provided by the manufacturer.

Immunocytochemistry. Adrenal glands were removed and fixed with Bouin's fluid, dehydrated, and embedded in paraffin under standard conditions. Four serial sections of $10 \mu \mathrm{m}$ thick were obtained; one of the serial section was stained by hematoxylin-eosin method.

The antibodies against $\mathrm{CgA}$ and $\mathrm{TH}$ were used as primary antibodies (see Fig. 1). Serial sections were simultaneously incubated overnight at room temperature in Tris-saline, $\mathrm{pH} 7.6$, containing anti-CgA (A-D) or anti-TH $(\mathrm{D}-\mathrm{H})$ diluted $1: 300$ and 1:8000, respectively. The procedure was followed by StreptABComplex Duet Reagent Set Mouse/Rabbit procedure (DAKO, Barcelona, Spain). The peroxidase reaction product was visualized through the standard diaminobenzidine reaction. Control experiments were performed with the omission of the primary antibodies.

HPLC analysis of CA. Adrenal medullae were triturated in an ice-cold lysis buffer containing perchloric acid $(0.05 \mathrm{~N})$, Triton X-100 (0.25\%) and dihydroxybenzylamine $(100 \mathrm{ng} / \mathrm{ml})$ as internal standard. The homogenate was centrifuged for $5 \mathrm{~min}$ at $10,000 \times \mathrm{g}$. Cleared supernatants were injected into a Shimatzu reverse-phase HPLC system with an electrochemical detector as described previously (Borges et al., 1986).

Conventional amperometry. Carbon fiber microelectrodes of $5 \mu \mathrm{m}$ radius (Thornel P-55; Amoco, Greenville, SC) were prepared as described previously (Kawagoe et al., 1993). Calibration of the microelectrodes was essential to assure the reproducibility of results. Electrodes were tested in a flow cell and accepted for cell studies when the application of noradrenaline $(50 \mu \mathrm{M})$ resulted in an oxidation current of $300-400 \mathrm{pA}$, which should be reduced by $80-100$ pA under stop-flow conditions.

Amperometric measurements were performed with the carbon fiber microelectrode gently touching the cell membrane using an Axopatch 200B (Molecular Devices, Foster City, CA) (Machado et al., 2000). Cell secretion was stimulated by 5 s pressure ejections of $5 \mathrm{mM} \mathrm{Ba}^{2+}$ from a micropipette situated at $40 \mu \mathrm{m}$ from the cell. All recordings were performed under stopping flow conditions.

Amperometric data analysis. Signals were low-pass filtered at $1 \mathrm{kHz}$ and collected at $4 \mathrm{kHz}$ using locally written software (LabView for Macintosh; National Instruments, Austin, TX). Data analysis was performed using locally written macros for IGOR (Wavemetrics, Lake Oswego, OR) (Segura et al., 2000). These macros and their user manual can be freely downloaded from the web address http://webpages.ull.es/users/ rborges/Downloads.html.

The analysis of individual exocytotic events included the measurement of the following parameters: $I_{\max }$, maximum oxidation current, expressed in picoamperes; $t_{1 / 2}$, spike width at half height, expressed in milliseconds; $Q$, spike net charge, expressed in picocoulombs; $m$, ascending slope of spike, expressed in nanoamperes/second (for details, see Machado et al., 2000; Segura et al., 2000). To analyze the falling part of the spike, two extra measurements were taken: $\mathrm{Ft}_{1}$ and $\mathrm{Ft}_{2}$ (falling times 1 and 2 ), as the time from the spike maximum point to reach the $I_{\max } / e$ and the $I_{\max } / 1-e$ points of the spike, respectively.

To overcome day-to-day variations in electrode sensitivity and on the secretory responses, the recordings were alternated between $\mathrm{CgA}-\mathrm{KO}$ and WT cells. We used the average values of spikes recorded from single cells to estimate one statistic per cell $(n)$. The kinetic parameters were calculated as mean values from at least 20 spikes/cell, and we compared this statistic between WT (mice with isogenic background) and CgA-KO cells (Colliver et al., 2001).

Patch amperometry. The procedure for electrode and pipette construction exactly followed that described previously (Dernick et al., 2005). Capacitance measurements were conducted using an Axopatch 200B. The amplifier was modified following instructions from the manufacturer to deliver calibration pulses of $10 \mathrm{fF}$. A VA-10 potentiostat (NPI Electronics, Tamm, Germany) was modified to use the chassis of the BNC (British Navy Connector) of the preamplifier as direct ground.

A polyethylene insulated carbon fiber was used as the working electrode for electrochemical detection of the CA diffusing from the cytosol and aspirated into the patch pipette at the time of cell membrane rupture. A constant voltage of $+700 \mathrm{mV}$ was applied to the carbon fiber microelectrode. Because the ground electrode was inside the patch pipette, a $\mathrm{Ag} / \mathrm{AgCl}$ electrode connected to the input of an Axopatch 200B amplifier was in contact with the bath buffer (Krebs-HEPES). The sine wave voltage signal $(50 \mathrm{mV}, 20 \mathrm{kHz})$ and its split into its real and imaginary components were visualized by means of a lock-in amplifier (SR 830; Stanford Research Instruments, Sunnyvale, CA) as described previously (Dernick et al., 2005). Recording pipettes were coated with wax and fire polished. The typical pipette resistance in the bath was $1.5-4 \mathrm{M} \Omega$. Signals from different channels were collected at $10 \mathrm{kHz}$ using locally written 


\section{anti-CgA}

WT

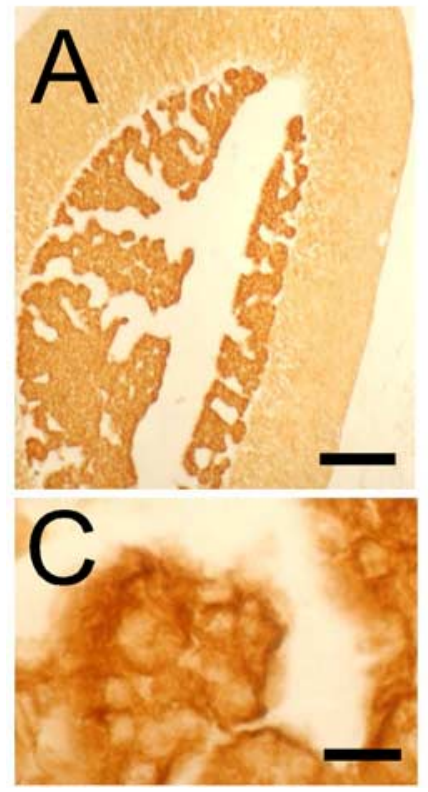

$\mathrm{CgA}-\mathrm{KO}$
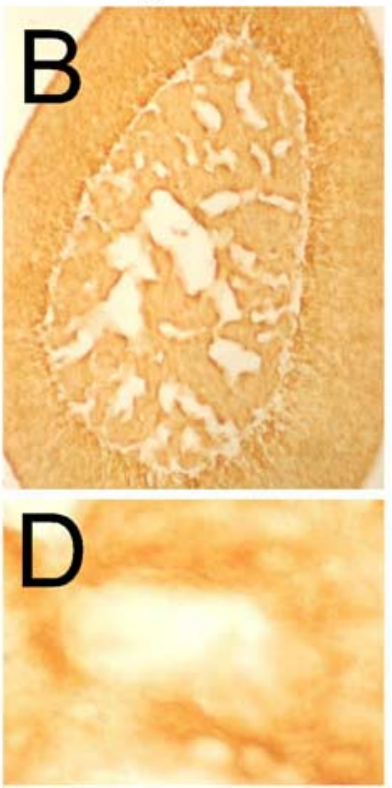

anti-TH

WT

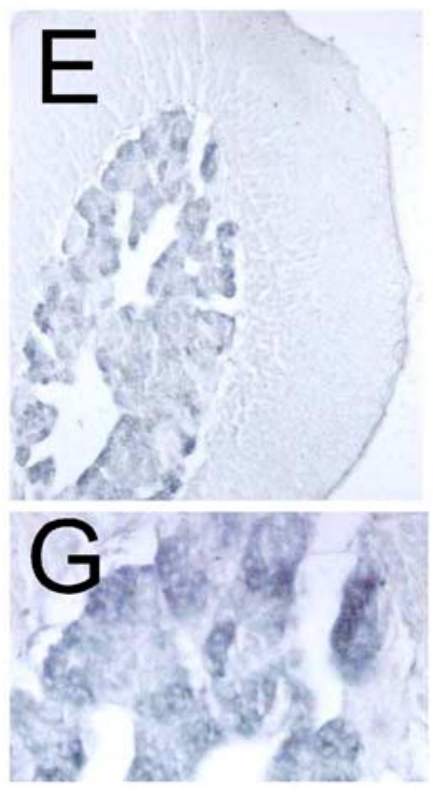

Figure 1. Immunohistochemical characterization of (gA-KO mice. Adrenal gland sections were compared with their control strains (isogenic background, WT). Primary polyclonal rabbit antibodies against $\mathrm{CgA}$ or monoclonal anti-mouse against $\mathrm{TH}$ were used. As a secondary antibody we used an anti-rabbit or anti-mouse lgG labeled with horseradish peroxidase. The figure shows sections of the mouse adrenal gland immunostained with anti-CgA or anti-TH. Scale bars: (in $A) A, B, E, F, 300 \mu \mathrm{m}$; (in $C) C, D, G, H, 50 \mu \mathrm{m}$.

A

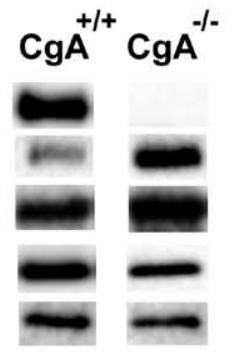

Anti-CgA

Anti-CgB

Anti-Sgll

Anti-TH

Anti- $\alpha-$ Tub
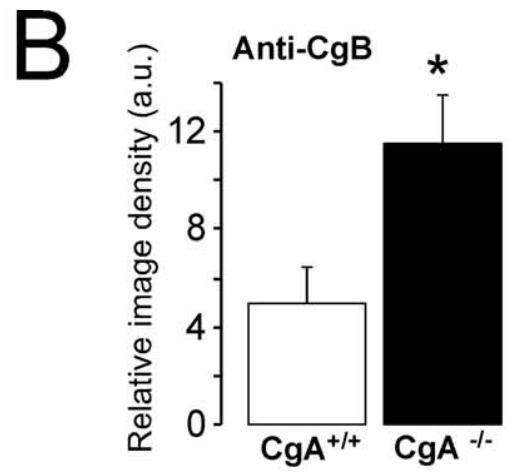

Anti-Sg II

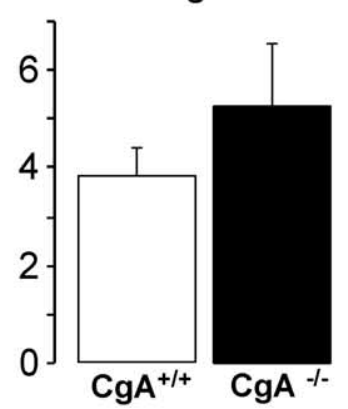

Anti-TH

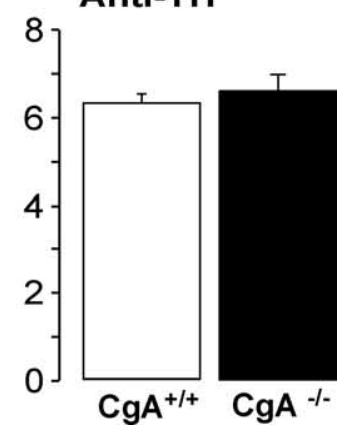

Figure 2. Changes in the expression of granins observed in CgA-KO $(-/-)$ versus WT $(+/+)$ mice. $A$, Western blots were performed on CgA-KO adrenal medullary homogenates using anti- $\alpha$-tubulin as an internal control. $\boldsymbol{B}$, Results (mean \pm SEM) from six different analyses were pooled. ${ }^{*} p<0.05$, Student's $t$ test.

acquisition software (LabView). Data analysis was performed using macros for IGOR.

The pipette solution contained (in $\mathrm{mm}$ ) $135 \mathrm{NaCl}, 5 \mathrm{KCl}, 5 \mathrm{CaCl}_{2}, 1$ $\mathrm{MgCl}_{2}, 5$ tetraethylammonium (TEA), and 10 HEPES, adjusted to $\mathrm{pH}$ 7.35.

Intracellular patch electrochemistry. Whole-cell patch amperometry was adapted from (Mosharov et al., 2003). The patch pipette solution contained (in mM) $135 \mathrm{NaCl}, 5 \mathrm{KCl}, 5 \mathrm{CaCl}_{2}, 1 \mathrm{MgCl}_{2}, 5 \mathrm{TEA}$, and 10 HEPES, adjusted to $\mathrm{pH} 7.35$. The osmolarity of all solutions used was in the range of $300-315 \mathrm{mOsm}$.

Statistics. Data sets are expressed as mean \pm SEM. The statistical significance between groups of experiments was assessed by the MannWhitney rank sum or Student's $t$ test. For multiple contrasts, like in Figures 5 and 7, a Bonferroni correction (Kleinbaum et al., 1998) was applied, $\alpha$ at 0.005 was considered to be statistically significant.

\section{Results}

Phenotype of CgA-KO (-/-) mice

The CgA null $(-/-)$ state was confirmed by PCR genotyping compared with the wild-type $(+/+)$ coisogenic strain.

The gross morphological observation did not show any apparent differences in the size of the medulla or cortex between CgA-KO and WT animals (10 and 12 adrenals from each strain). In situ immunohistochemistry (Fig. 1) and immunoblot analysis (Fig. 2) confirmed the lack of adrenal CgA expression. The expression of $\mathrm{CgB}, \mathrm{SgII}$, and $\mathrm{TH}$ was also assessed by immunoblot. $\mathrm{KO}$ mice showed overexpression of $\mathrm{CgB}$, a slight, but nonsignificant, increase in SgII and unchanged expression of $\mathrm{TH}$ when compared with WT animals. Analysis by HPLC revealed a signif- 

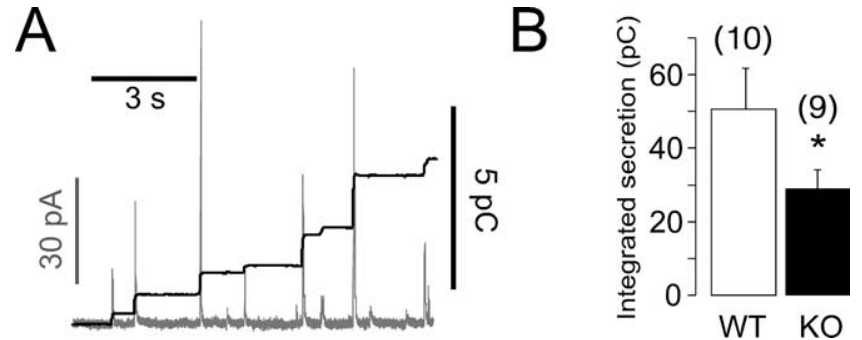

Figure 3. Secretory responses of CgA-KO chromaffin cells studied with amperometry. A, Representative trace (gray) showing the amperometric recording from an isolated cell stimulated for $5 \mathrm{~s}$ with $5 \mathrm{~mm} \mathrm{BaCl}$. Each spike represents the $\mathrm{CA}$ released from a single vesicle. The black outline shows the cumulative secretory response obtained by integration of the amperometric charge after baseline subtraction. $\boldsymbol{B}$, Total secretion (mean \pm SEM) comparing WT with CgA-KO cells; the cumulative charges were measured for 2 min after the stimulus and expressed in picocoulombs. The number of cells from each group is expressed in parentheses. ${ }^{*} p<0.05$, Student's $t$ test.

icant reduction in CA content $(p<0.05)$ in the adrenal medulla of the CgA-KO strains $(18.3 \pm 1.65 \mu \mathrm{g} \mathrm{CA} / \mathrm{mg}$ protein vs $27.03 \pm$ 2.36 in WT). However, the proportion of norepinephrine was higher in CgA-KO mice (46\%) than in the WT (38\%). The dopamine content tended to be higher in the adrenals of $\mathrm{KO}$ animals ( $1.8 \%$ vs $3.03 \%)$, although this difference was not significant.

\section{Secretion of CA from cultured chromaffin cells}

We used conventional amperometry to monitor the secretory responses of chromaffin cells. Cells from WT mice with isogenic background were used as control. Experiments were conducted on the same day by using the same carbon fiber electrode and alternating recordings from WT and CgA-KO cells. Figure $3 \mathrm{~A}$ shows a typical trace of an amperometric signal superimposed on its cumulative secretion recording from a CgA-KO mouse cell. The integral of amperometric traces followed a method to avoid the addition of charge that could result from an asymmetrical distribution of noise. This computer program can be downloaded free from the web-site cited in Materials and Methods. Figure $3 B$ shows the averaged net secretion.

We used $\mathrm{BaCl}_{2}(5 \mathrm{~mm} / 5 \mathrm{~s})$ as an exocytotic secretory stimulus to reduce the number of overlapped spikes and to minimize the influence of other cellular mechanisms such as activation of nicotinic receptors or $\mathrm{Ca}^{2+}$ channels in determining the characteristics of the secretory events (Fig. $3 A$ ). The overlapping probability of two independent and undistinguished exocytotic events in our experimental conditions was very low $(p=0.021 ; n=983$ events). The distribution of spike frequency during the $2 \mathrm{~min}$ after a $5 \mathrm{~s} \mathrm{BaCl}_{2}$ pulse to 10 chromaffin cells from WT mice is shown in Figure 4. There were no differences between the temporal distribution patterns of secretory spikes from WT- and CgA-KO-cells (data not shown) $(p=0.417$, spike firing recorded from 10-12 cells from each cell type).

Cells from CgA-KO mice released $41 \pm 8 \%$ less CA than cells from WT animals (Fig. 3B). This reduction was not caused by a reduction in the number of secretory spikes detected in 2 min records (126.4 $\pm 24.8 \mathrm{KO}$ vs $117.4 \pm 17.9 \mathrm{WT})$, but to a reduction in the net amount of CA released per quantum.

The different parameters obtained from individual spikes can be analyzed either by grouping all spikes from all cells from each condition (KO vs WT) or on a cell basis, where the averaged parameters from each cell were used single data. We used the latter method because it is more robust. The kinetic characteristics of exocytotic events from CgA-KO cells were different from

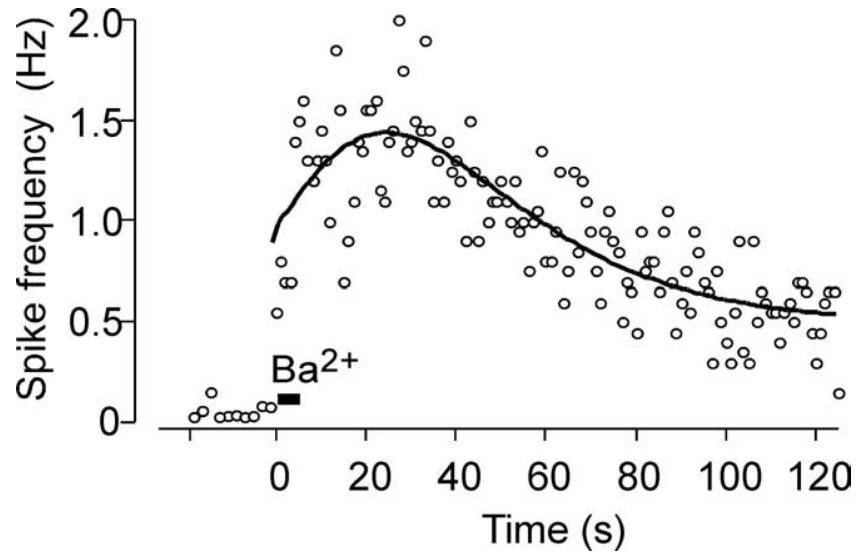

Figure 4. Quantal secretion of catecholamines from adrenal chromaffin cells. Probability distribution of secretory events during a 2 min recording period. Secretion was elicited by pressure injection of $5 \mathrm{~mm} \mathrm{Ba}^{2+}$ for $5 \mathrm{~s}$ from a micropipette placed $40 \mu \mathrm{m}$ away from the cell. Each circle represents the average of spike frequencies recorded within $1 \mathrm{~s}$ bins from control cells $(n=10)$. The solid line is the curve fitting. The distribution of probability reaches a maximum at $20 \mathrm{~s}$ after stimulation by $\mathrm{BaCl}_{2}$.

those obtained from WT cells under these higher stringency conditions (Table 1).

A careful analysis of individual exocytotic events shows that the changes caused by the lack of CgA affect preferentially granules with the largest CA content (Fig. 5). This representation indicates that the spikes from CgA-KO animals with similar quantal size have larger $I_{\max }$ than WT cells.

Table 1 also shows that the apparent quantal size $(Q)$ was reduced to $66 \%$ of WT, which roughly coincides with the reduction of the total amount of CA secreted. The secretory spikes from CgA-KO cells animals did not exhibit changes in the ascending part $(m)$, but a reduction in the spike duration $\left(t_{1 / 2}\right)$ accompanied by a faster decay $\left(\mathrm{Ft}_{1}\right.$ and $\left.\mathrm{Ft}_{2}\right)$.

The analysis of the decaying part of secretory spikes suggests that a single phenomenon governs the late stage of spikes. The dissociation of the CA from the vesicular matrix occurs at a faster rate in $\mathrm{CgA}-\mathrm{KO}$ cells, as $\mathrm{Ft}_{1}$ and $\mathrm{Ft}_{2}$ were significantly shorter (Table 1). It is unlike that these changes were caused by different fusion pore kinetics because, at this late stage, the fusion pore should be fully expanded (see Fig. 9) therefore not influencing the rate of diffusion of CA toward the electrode.

\section{The effect of CA overload}

The rate-limiting step in the synthesis of CA is the activity of the enzyme TH. It can be bypassed by cell incubation with L-DOPA, which is rapidly transformed into CA (Mosharov et al., 2003). We incubated chromaffin cells with $100 \mu \mathrm{M} \mathrm{L}$-DOPA for $90 \mathrm{~min}$ and then studied the secretory events with amperometry, starting immediately after L-DOPA removal from the incubation medium. The effects on quantal size and $I_{\max }$ are summarized in Figure 6. Figure $6 B$ shows the reduction in the spike charge between untreated cells between WT and CgA-KO.

This treatment resulted in a net increase of the $I_{\max }$ and of the $Q$ in cells from WT animals, with a modest increase in $t_{1 / 2}$. When the CA precursor overload was performed in CgA-KO cells there was an increased $I_{\max }$ to a similar extent as in cells from WT animals. However, L-DOPA did not change the $Q$ of the spikes in the CgA-KO cells. These data suggest important differences between WT and CgA-KO cells in their ability to store the newly synthesized CA by chromaffin vesicles. This dissociation between the vesicular CA content and the $I_{\max }$, in response to L-DOPA 
Table 1. Characteristics of secretory spikes from WT and CgA-KO mice

\begin{tabular}{lllllll}
\hline & $\begin{array}{l}I_{\max } \\
(\mathrm{pA})\end{array}$ & $\begin{array}{l}t_{1 / 2} \\
(\mathrm{pC})\end{array}$ & $\begin{array}{l}M \\
(\mathrm{~ms})\end{array}$ & $\begin{array}{l}\mathrm{Ft}_{1} \\
(\mathrm{~ms})\end{array}$ & $\begin{array}{l}n \text { F spikes } \\
(\mathrm{ms})\end{array}$ \\
\hline WT & $43.0 \pm 3.6$ & $0.67 \pm 0.08$ & $14.7 \pm 2.3$ & $15.8 \pm 2.4$ & $17.7 \pm 1.6$ & $38.4 \pm 2.6$ \\
CgA-KO & $42.3 \pm 6.0$ & $0.44 \pm 0.04^{* *}$ & $9.8 \pm 0.7^{*}$ & $14.7 \pm 2.4$ & $12.9 \pm 1.9^{*}$ & $31.0 \pm 2.6^{*}$ \\
\hline
\end{tabular}

For an explanation, see Materials and Methods and Segura et al. (2000). Shown are results from one typical experiment from a culture of both cell strains performed in parallel. Experiments were repeated using cells from five different cultures with similar results. The quantitative differences observed between data from WT from different cell cultures did not allow pooling data. Data are expressed in the units described.

${ }^{*} p<0.05 ;{ }^{* *} p<0.01$ (Mann-Whitney $U$ test).

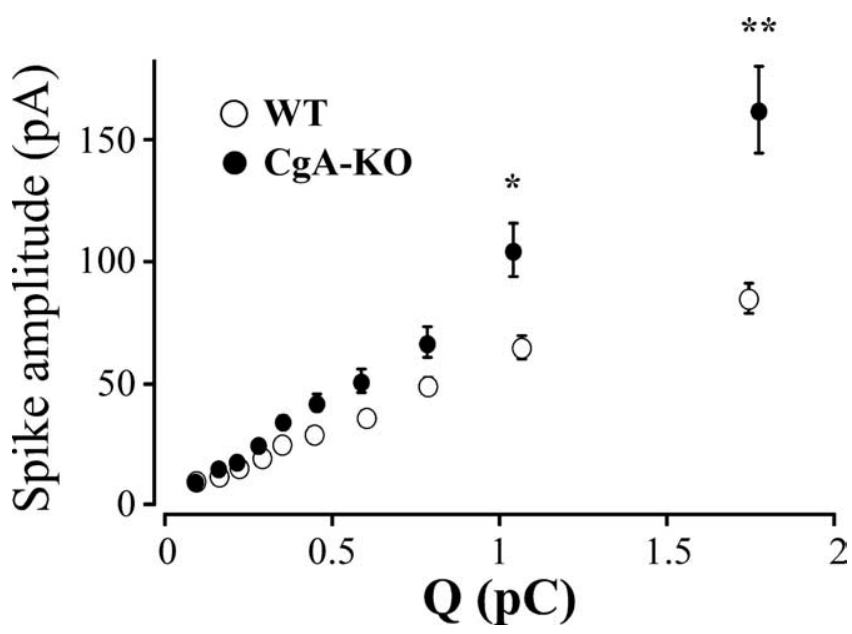

Figure 5. Spike amplitude versus quantal size of secretory spikes from CgA-KO and WT mice. All spikes (from WT and $(\mathrm{gA}-\mathrm{KO}$ ) were pooled regardless of whether they were from WT or KO cells and then distributed into 10 intervals of increasing charge containing the same number of spikes. The spikes were then split into WT and $K 0$ and their $I_{\text {max }}$ (mean $\left.\pm S E M\right)$ analyzed. Note that, at similar quantal size, the spikes from CgA-KO have a larger $I_{\max }$ than WT. ${ }^{*} p<0.005$; ${ }^{* *} p<0.001$, Mann-Whitney $U$ test with Bonferroni correction. Data are averaged from the spikes accounted in Table 1.

overload, can be best observed in the Q-interval plots from Figure 7. In WT mice, as also occurs in bovine chromaffin cells, $I_{\max }$ and $Q$ are tightly dependent parameters and larger $I_{\max }$ is generally associated to spikes with a large Q. L-DOPA should not change this relation (Colliver et al., 2000); however, in CgA-KO cells this ratio was altered and similar quantum sizes were accompanied by an abnormally large $I_{\max }$.

The results shown on Figure 6 confirm that chromaffin granules lacking in CgA cannot take-up more CA even under conditions of overload. We conducted additional experiments to explore whether the apparent impairment in monoamine accumulation in the $\mathrm{CgA}-\mathrm{KO}$ cells caused changes in the concentrations of cytosolic free CA after L-DOPA incubation using the patch-amperometry technique in the configuration of the whole cell. Figure $8 \mathrm{~A}$ shows the experimental approach used. The cell membrane at the tip of the pipette was broken by suction, as confirmed by the capacitance jump (Fig. $8 \mathrm{~B}$ ). The electrode immediately recorded a large amperometric current that decayed exponentially as the CA that entered into the pipette during the suction and those diffusing from the cytosol were being oxidized (Fig. $8 B$ ). Note the presence of amperometric spikes in the zoomed trace. Their kinetic characteristics are similar to the spikes observed in the cell-attached configuration of patchamperometry (data not shown). The origin of these spikes will be discussed later.

We compared the cytosolic free CA from WT- with CgA-KOcells in the absence and in the presence of L-DOPA. We added the monoamine oxidase $(\mathrm{MAO})$ inhibitor pargyline $(10 \mu \mathrm{M})$ to avoid changes in free cytosolic CA that could be originated from differ-

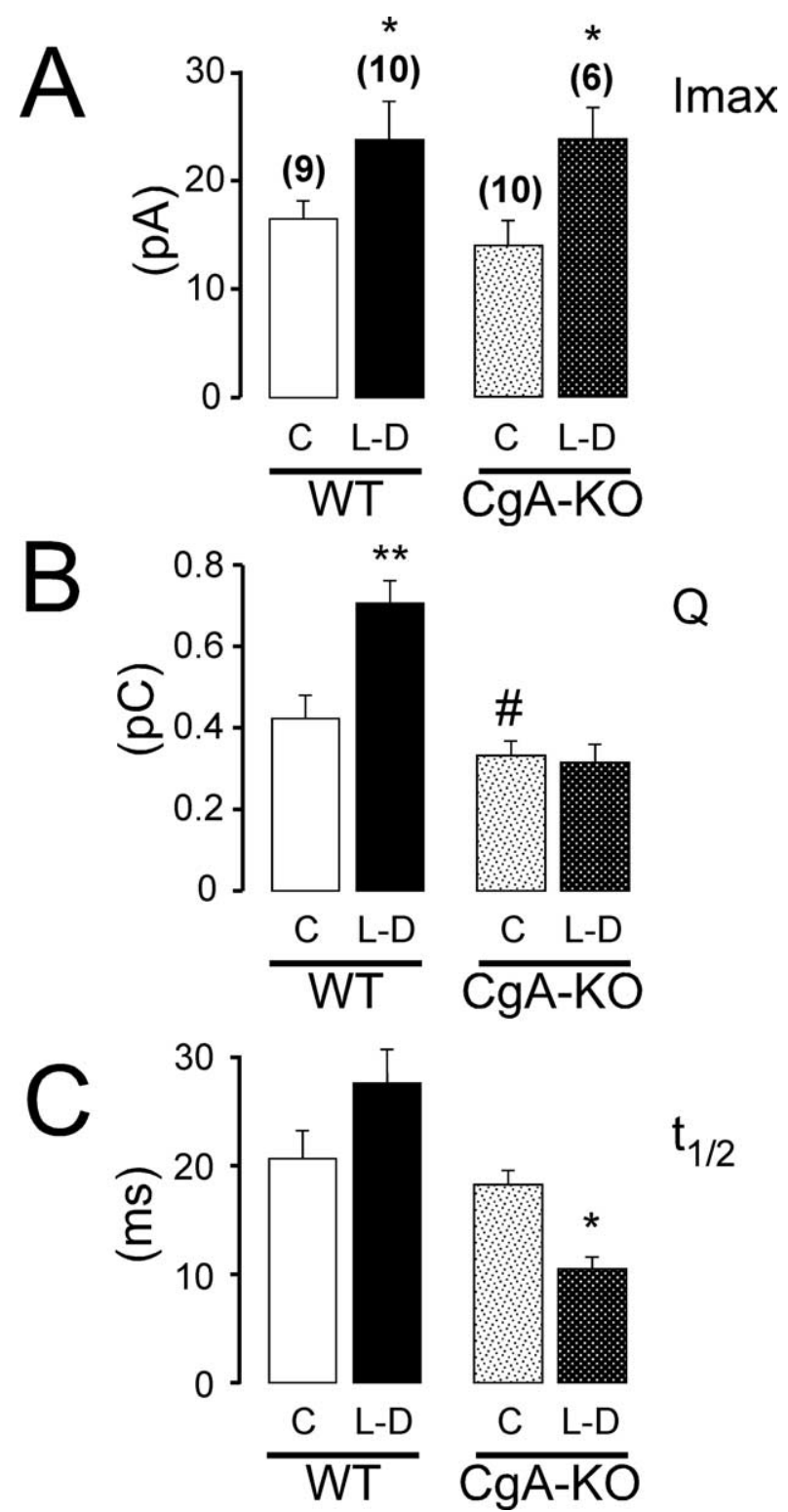

Figure 6. Effects of L-DOPA incubation on the secretory spikes from WT and CgA-KO cells. Cells attached to coverslips were incubated in a culture medium containing 0 (C) or $100 \mu \mathrm{m}$ L-DOPA (L-D) for $90 \mathrm{~min}$ at $37^{\circ} \mathrm{C}$. The coverslips were then washed twice with Krebs-HEPES buffer and used for conventional amperometry. $\boldsymbol{A}-\boldsymbol{C}$, The effects of $\mathrm{L}$-DOPA on spike height $(\boldsymbol{A})$, quantal size $(\boldsymbol{B})$, and $\mathrm{t}_{1 / 2}(\boldsymbol{C})$. Numbers in parentheses indicate the number of cells used. ${ }^{*} p<$ 0.05 and ${ }^{* *} p<0.01$ (Student's $t$ test) when comparing effects of $\mathrm{L}-\mathrm{DOPA}$ incubation against the corresponding control; ${ }^{\#} p<0.05$ when comparison was done between untreated $(\boldsymbol{C})$ cells from WT- and CgA-KO-animals.

ences in MAO activity from both cells. Figure $8 C$ shows the time course of the decay of the free CA in WT cells from the moment the membrane is broken, from both the L-DOPA-incubated and un-incubated cells. A marked difference is observed between the 

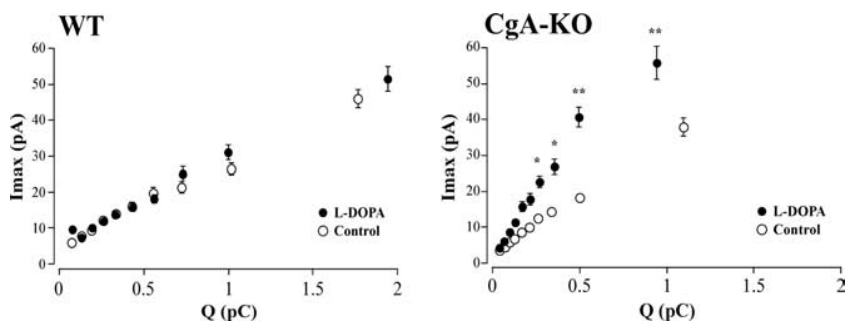

Figure 7. Effects of L-DOPA overload on the relation between catecholamine content of vesicles $(Q)$ and the maximal concentration reaching the carbon fiber electrode $\left(I_{\max }\right)$. Plots show the relation of spike amplitude versus quantal size in the absence (control) and after cell incubation with $100 \mu \mathrm{mL}$-DOPA for $90 \mathrm{~min}$ in WT cells ( $n=1483$ spikes from 15 cells; left) and CgA-K0 cells ( $n=1127$ spikes from 13 cells; right). The description of the method to perform this analysis is in the legend of Figure 5 . Note that the tight relation between $I_{\max }$ and $Q$ in the spikes recorded from WT cells did not occur in the CgA-KO. In these cells, L-DOPA treatment promoted the increase in the $I_{\max }$ from vesicles of similar quantal size. ${ }^{*} p<0.005$; ${ }^{* *} p<$ 0.001, Mann-Whitney $U$ test with Bonferroni correction.

A

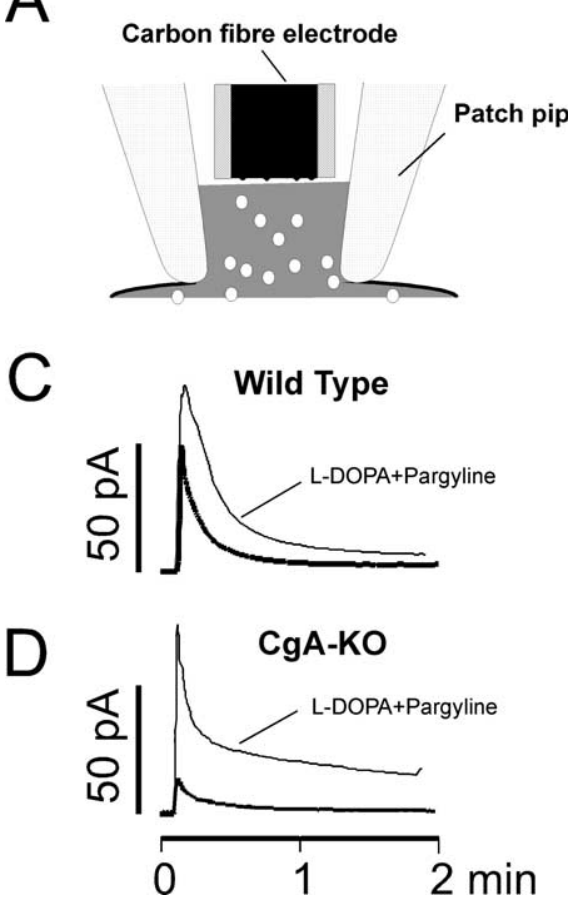

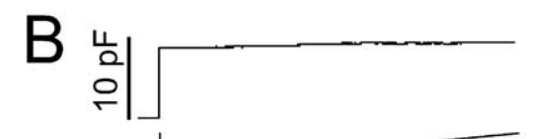
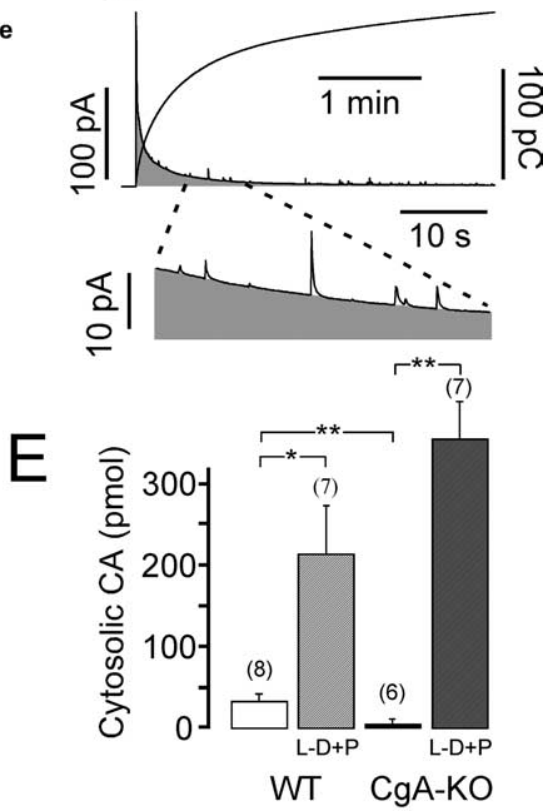

Figure 8. L-DOPA overload suggests a lack of accumulation of newly synthesized CA (after overload) in vesicles from the CgA-KO mouse. A, Diagram showing the experimental approach using patch amperometry in the whole-cell configuration. The plasma membrane was ruptured by suction and a whole-cell configuration was achieved. This allows secretory vesicles, $C A$, and other soluble molecules to diffuse from the cytosol into the pipette. $\boldsymbol{B}$, The capacitance jump indicates the opening of the plasma membrane to the whole cell configuration. The cytosolic oxidable molecules are monitored as a rapid increase in current followed by a slow decaying wave by the amperometry microelectrode. Observe the presence of amperometric spikes in the zoomed portion of the decaying slope. After spike area subtraction, the total area of this oxidation current wave (gray) was used as a measure of the amount of cytosolic free CA depicted as the smooth ascending line. $C$, Averaged time course of free CA levels in cells from WT mice not exposed to L-DOPA (thick trace, $n=8$ ) and from other cells after L-DOPA + pargyline treatment (thin trace, $n=7$ ). $\boldsymbol{D}$, As in C but in (gA-K0 cells ( $n=6$ and 7 cells). $\boldsymbol{E}$, Average values from integration of the curves from $\boldsymbol{C}$ and $\boldsymbol{D}$. Numbers in parentheses indicate the number of cells used. ${ }^{*} p<0.05 ;{ }^{* *} p<0.01$, Student's $t$ test.

WT and the CgA-KO cells. The CgA-KO cells had a lower content of cytosolic CA under basal conditions than cells obtained from WT animals, but they reached higher CA levels than their WT cells after exposure to L-DOPA (Fig. $8 D$ ). The integrals from these curves are shown in Figure $8 E$, note the pronounced differences under basal conditions and after L-DOPA overload.
The capacitance jump measured during the exocytotic event, using patch amperometry, indicated that the volume (vesicular membrane surface) of the secreting vesicles was not different from its corresponding control when CgA was absent (data not shown). The ratio between CA charge and vesicle size shows that vesicles from CgA-KO cells have an apparently lower amine concentration (Table 3 ).

\section{Discussion}

Quantal transmission relies on the exocytosis of discrete packages of neurotransmitters, and the amount of active transmitter accumulated inside secretory vesicles (quantum size) determines the efficacy of synaptic transmission However, the cellular mechanisms that concentrate neurotransmitters inside secretory organelles are still elusive and are far from been clarified. Because of the high abundance of Cgs within the chromaffin vesicles (Helle et al., 1985) they were thought to play a major role in the accumulation of amines inside these organelles. Vesicular CA reaches very high concentrations [calculations range from $0.8 \mathrm{~m}$ (Table 3) to $1 \mathrm{~m}$ (Albillos et al., 1997)], values that greatly exceed the osmolarity of the cytosol. The intravesicular mixture of amines, peptides, ATP, $\mathrm{Ca}^{2+}$, ascorbic acid, and granins may form a storage complex in vitro (Berneis et al., 1973; Kopell and Westhead, 1982); however, no evidences based on direct measurements have been reported. The presence of intravesicular factor(s) that delay the release of CA was first suggested by the observation of discrepancies between the predicted and the observed diffusion of CA toward the amperometric electrode (Jankowski et al., 1993; Schroeder et al., 1996). Several experimental maneuvers including changes in the extracellular $\mathrm{pH}$ and ionic composition (Jankowski et al., 1994), intravesicular $\mathrm{pH}$ (Camacho et al., 2006), or osmotic pressure of the extracellular medium (Borges et al., 1997) pointed to the presence of a functional gel-like substance inside the vesicles. The analogy of chro- 
maffin granules with mast cells granules (Pihel et al., 1996), where amines are bound to a heparan sulfate matrix (Fernandez et al., 1991) has already been made. Because the anionic macromolecular matrix is mainly composed of Cgs, an obvious approach to test the role of Cgs in the accumulation of amines, in chromaffin granules, is to generate animals lacking Cgs. In the present communication, we have used CgA-KO mice to establish, for the first time, the role of $\mathrm{CgA}$ in the accumulation of CA inside the vesicle and their release on exocytosis.

The Cgs CgA, CgB, and SgII are the major soluble core protein components of chromaffin granules. Although structurally different, all granins share some common properties such as their acidic $\mathrm{pH}$ and their ability to bind amines. Chromogranin A binds CA with low affinity $(\mathrm{Kd}=2.1 \times$ $10^{-3} \mathrm{M}$ ) but high capacity ( $32 \mathrm{~mol} \mathrm{CA} / \mathrm{mol}$ CgA) (Videen et al., 1992), and a binding complex within the vesicle core may be nucleated by Cgs (Berneis et al., 1973). We found that $\mathrm{CgA}-\mathrm{KO}$ mice clearly overexpress $\mathrm{CgB}$, and perhaps SgII, thus indicating the existence of counter-regulatory mechanisms of Cgs expression (Fig. 1). Because Cgs share general polyanionic properties, the full extent of their functional roles cannot be completely established using only the CgA-KO mice. Indeed, siRNA-mediated disruption of the biosynthesis of either $\mathrm{CgA}$ or $\mathrm{CgB}$ may impair the formation of CA storage vesicles of cells (Huh et al., 2003).

The overall secretion of CA was substantially reduced in CgA-KO cells (Fig. 3). This finding, coupled with the quantal characteristics of single exocytotic events (Table 1), suggests that $\mathrm{CgA}$ is crucial in the process of accumulation and secretion of vesicular amines. The reduction in the net CA release observed in $\mathrm{CgA}-\mathrm{KO}$ was not caused by a lower rate of vesicle fusion, but by the lower content of CA within each vesicle (Table 1). The single event analysis of $\mathrm{CgA}-\mathrm{KO}$ also provides some additional relevant observations: the reduction in $\mathrm{Q}$ was not associated with a reduction in the $I_{\max }$, but rather with a reduction in the spike duration. The shorter falling times $\left(\mathrm{Ft}_{1}\right.$ and $\left.\mathrm{Ft}_{2}\right)$ of secretory spikes from CgA-KO mouse cells (Table 1) suggest a faster diffusion because of a deficient retention ability of the intravesicular matrix. This could be expected if, in the absence of $\mathrm{CgA}$, the remaining matrix has a lower affinity for CA, or a decrease in the number of CA binding sites resulting in a larger proportion of free vesicular amines. It would probably be assimilated to the "halo" observed in EM micrographs after L-DOPA incubation (Colliver et al., 2000). The latter mechanism may underlie the fact that the consequences of CgA ablation were more evident in the largest vesicles (Fig. 5).

The decaying slope is much steeper (lesser restriction to diffusion) in cells from CgA-KO animals than in WT, this constant rate of release suggests that CA have been released faster by diffusion from/through a "weaker" vesicular matrix. Together, these data indicate that the absence of CgA markedly reduces the ability of the vesicular matrix to bind and retain $\mathrm{CA}$, resulting in a shortening of the period for each releasing event. The results
Table 2. Prespike characteristics measured with patch amperometry

\begin{tabular}{llcll}
\hline & WT & $n$ events & CgA-K0 & $n$ events \\
\hline$\Delta t$ (ms) & $7.11 \pm 0.29$ & 111 & $10.79 \pm 0.73^{*}$ & 52 \\
$t_{\text {pore dilatation }}{ }^{a}(\mathrm{~ms})$ & $2.89 \pm 0.22$ & 43 & $2.53 \pm 0.31$ & 18 \\
\hline$\Delta{ }^{2}$
\end{tabular}

$\Delta t$ was calculated by measuring the time from the capacitance jump to the beginning of the amperometric spike ${ }^{a}$ Measured at $500 \mathrm{pS}$ of fusion pore conductance. Not all detected capacitance steps had measurable fusion pores. ${ }^{*} p<0.05$, Student's $t$ test.

Table 3. Characteristics of exocytosis from WT and CgA-KO mice obtained with patch amperometry

\begin{tabular}{lllll}
\hline & WT & $n$ events/cells & CgA-K0 & $n$ events/cells \\
\hline$Q$ (pC) & $1.81 \pm 0.09$ & $296 / 15$ & $1.31 \pm 0.09^{*}$ & $171 / 10$ \\
C (fF) & $0.52 \pm 0.02$ & $296 / 15$ & $0.58 \pm 0.03$ & $171 / 10$ \\
Q/C (M) & $0.87 \pm 0.06$ & $296 / 15$ & $0.53 \pm 0.02^{*}$ & $171 / 10$ \\
\hline
\end{tabular}

The CA concentration (expressed in molars) was the ratio between $\mathrm{Q}$ (moles) and vesicle volume from capacitance (C) changes.

${ }^{*} p<0.05$, Student's $t$ test.

obtained also provide direct evidences on the implication of the vesicle matrix in the control of the kinetics of exocytosis (Schroeder et al., 1996; Marszalek et al., 1997; Borges et al., 2000).

The ability of vesicles to accumulate amines was impaired in the absence of CgA (Fig. 6). L-DOPA incubation caused an increase in $\mathrm{I}_{\max }$ both in WT and CgA-KO cells, probably caused by a larger free CA fraction in the vesicles. The $\mathrm{I}_{\max }$ and the $\mathrm{Q}$ are tightly related parameters and a change in the size of one is usually accompanied by a proportional effect in the other, this also normally occurs after L-DOPA treatment. However, this relation dramatically changes in CgA-KO cells where the detected CA released from vesicles was secreted much faster than untreated cells (Fig. 6). Surprisingly, the CA content did not change in 
CgA-KO cells after L-DOPA overload indicating full saturation of the vesicular cargo.

It has been shown previously, using intracellular cyclic voltammetry, that chromaffin cells rapidly convert L-DOPA into CA (Larsen et al., 2006). We observed, using intracellular electrochemistry, an increase of cytosolic CA on L-DOPA in CgA-KO cells. These findings reinforce the hypothesis that the accumulation of CA in these vesicles is impaired (Fig. 8). Surprisingly, the basal levels of intracellular CA were lower in CgA-KO cells when compared with WT cells. Although we do not have a definite explanation for this consistent finding, we suspect that it could be caused by an effect on the TH activity.

The time course of the measured cytosolic CA was slower than described previously (Mosharov et al., 2003); these discrepancies could be explained by a different morphology of the pipette tips. Nevertheless, our data reinforce the notion that the accumulation of CA by chromaffin vesicles is impaired in the absence CgA.

The amperometric trace also shows the presence of spikes (Fig. $8 \mathrm{~B}$ ). The origin of these exocytotic-like phenomena could be caused by the burning of vesicles against the carbon fiber electrode as was suggested by Sulzer's group (Mosharov et al., 2003), but it is also possible that the vesicles could be fusing with broken cell membrane at the pipette tip (i.e., undergoing exocytosis). We favor the latter possibility because the kinetics properties of these secretory spikes were similar to those obtained in the cell-attached configuration, where the carbon fiber tip is situated 3-6 $\mu \mathrm{m}$ away from the cell membrane and because some of them include foot.

The ascending limb of secretory spikes from WT and CgA-KO cells were similar (Table 1), and no differences were observed in the fusion pore kinetic parameters (Table 2). The major differences in spikes from $\mathrm{CgA}-\mathrm{KO}$ cells correspond to a net decrease in CA content and in a faster decay phase of secretory spikes. The fusion pore kinetics seems not to be implicated in the changes observed in exocytosis. The comparison of the time course of the three traces from Figure 9 clearly shows that fusion pore expansion (dashed line marked as i) occurs well before the decay phase of the secretory spike (dashed line marked as iii) to contribute to the changes observed in spikes from CgA-KO cells (Table 1). The only remarkable difference observed in the fusion pore kinetics was the delay in the formation of the fusion pore and the detectable amperometric spike (Table 2). We hypothesize that a vesicle without CgA has impaired swelling capability that culminates in delaying the release of CA.

Our data provide the first direct evidence implicating $\mathrm{CgA}$ in the vesicular storage and in the exocytotic release of CA. The aggregation of CA to chromogranins represents the main mechanism used by secretory vesicles to concentrate large amounts of amines. Although the lack of CgA may be partially compensated by the overexpression of the other granins (especially $\mathrm{CgB}$ ), nonetheless the cargo capacities of secretory vesicles from CgA-KO cells are seriously impaired. Because common genetic variation at the Chga locus in humans results in interindividual differences in CgA biosynthesis and release (Wen et al., 2004), our results provide mechanistic implications for human autonomic physiology and diseases.

\section{References}

Albillos A, Dernick G, Horstmann H, Almers W, Alvarez de Toledo G, Lindau M (1997) The exocytotic event in chromaffin cells revealed by patch amperometry. Nature 389:509-512.

Berneis KH, Goetz U, Da Prada M, Pletscher A (1973) Interaction of aggre- gated catecholamines and nucleotides with intragranular proteins. Naunyn Schmiedebergs Arch Pharmacol 277:291-296.

Borges R, Sala F, Garcia AG (1986) Continuous monitoring of catecholamine release from perfused cat adrenals. J Neurosci Methods 16:289-300.

Borges R, Travis ER, Hochstetler SE, Wightman RM (1997) Effects of external osmotic pressure on vesicular secretion from bovine adrenal medullary cells. J Biol Chem 272:8325-8331.

Borges R, Machado JD, Alonso C, Brioso MA, Gomez JF (2000) Functional role of chromogranins. The intragranular matrix in the last phase of exocytosis. Adv Exp Med Biol 482:69-81.

Brekke JF, Kirkeleit J, Lugardon K, Helle KB (2000) Vasostatins. Dilators of bovine resistance arteries. Adv Exp Med Biol 482:239-246.

Camacho M, Machado JD, Montesinos MS, Criado M, Borges R (2006) Intragranular $\mathrm{pH}$ rapidly modulates exocytosis in adrenal chromaffin cells. J Neurochem 96:324-334.

Colliver TL, Pyott SJ, Achalabun M, Ewing AG (2000) VMAT-Mediated changes in quantal size and vesicular volume. J Neurosci 20:5276-5282.

Colliver TL, Hess EJ, Ewing AG (2001) Amperometric analysis of exocytosis at chromaffin cells from genetically distinct mice. J Neurosci Methods 105:95-103.

Courel M, Rodemer C, Nguyen ST, Pance A, Jackson AP, O'Connor DT, Taupenot L (2006) Secretory granule biogenesis in sympathoadrenal cells: identification of a granulogenic determinant in the secretory prohormone chromogranin A. J Biol Chem 281:38038-38051.

Dernick G, Gong LW, Tabares L, Alvarez de Toledo G, Lindau M (2005) Patch amperometry: high-resolution measurements of single-vesicle fusion and release. Nat Methods 2:699-708.

Fernandez JM, Villalon M, Verdugo P (1991) Reversible condensation of mast cell secretory products in vitro. Biophys J 59:1022-1027.

Gleave TL, Beechey RB, Burgoyne RD (2001) Cysteine string protein expression in mammary epithelial cells. Pflugers Archiv Eur J Physiology 441:639-649.

Helle KB, Reed RK, Pihl KE, Serck-Hanssen G (1985) Osmotic properties of the chromogranins and relation to osmotic pressure in catecholamine storage granules. Acta Physiol Scand 123:21-33.

Hendy GN, Li T, Girard M, Feldstein RC, Mulay S, Desjardins R, Day R, Karaplis AC, Tremblay ML, Canaff L (2006) Targeted ablation of the chromogranin a (Chga) gene: normal neuroendocrine dense-core secretory granules and increased expression of other granins. Mol Endocrinol 20:1935-1947.

Huh YH, Jeon SH, Yoo SH (2003) Chromogranin B-induced secretory granule biogenesis: comparison with the similar role of chromogranin A. J Biol Chem 278:40581-40589.

Jankowski JA, Schroeder TJ, Ciolkowski EL, Wightman RM (1993) Temporal Characteristics of quantal secretion of catecholamines from adrenalmedullary cells. J Biol Chem 268:14694-14700.

Jankowski JA, Finnegan JM, Wightman RM (1994) Extracellular ionic composition alters kinetics of vesicular release of catecholamines and quantal size during exocytosis at adrenal-medullary cells. J Neurochem 63:1739-1747.

Kawagoe KT, Zimmerman JB, Wightman RM (1993) Principles of voltammetry and microelectrode surface states. J Neurosci Methods 48:225-240.

Kleinbaum D, Kupper K, Muller and Nizam A (1998) Applied regression analysis and other multivariable methods. Pacific Grove, CA: Duxbury.

Kopell WN, Westhead EW (1982) Osmotic pressures of solutions of ATP and catecholamines relating to storage in chromaffin granules. J Biol Chem 257:5707-5710.

Larsen KE, Schmitz Y, Troyer MD, Mosharov E, Dietrich P, Quazi AZ, Savalle M, Nemani V, Chaudhry FA, Edwards RH, Stefanis L, Sulzer D (2006) Alpha-synuclein overexpression in PC12 and chromaffin cells impairs catecholamine release by interfering with a late step in exocytosis. J Neurosci 26:11915-11922.

Machado JD, Segura F, Brioso MA, Borges R (2000) Nitric oxide modulates a late step of exocytosis. J Biol Chem 275:20274-20279.

Mahapatra NR, O'Connor DT, Vaingankar SM, Hikim AP, Mahata M, Ray S, Staite E, Wu H, Gu Y, Dalton N, Kennedy BP, Ziegler MG, Ross J, Mahata SK (2005) Hypertension from targeted ablation of chromogranin A can be rescued by the human ortholog. J Clin Invest 115:1942-1952.

Marszalek PE, Farrell B, Verdugo P, Fernandez JM (1997) Kinetics of release of serotonin from isolated secretory granules. I. Amperometric detection of serotonin from electroporated granules. Biophys J 73:1160-1168. 
Mosharov EV, Gong LW, Khanna B, Sulzer D, Lindau M (2003) Intracellular patch electrochemistry: regulation of cytosolic catecholamines in chromaffin cells. J Neurosci 23:5835-5845.

Nanavati C, Fernandez JM (1993) The secretory granule matrix: a fastacting smart polymer. Science 259:963-965.

Pihel K, Travis ER, Borges R, Wightman RM (1996) Exocytotic release from individual granules exhibits similar properties at mast and chromaffin cells. Biophys J 71:1633-1640.

Schroeder TJ, Borges R, Finnegan JM, Pihel K, Amatore C, Wightman RM (1996) Temporally resolved, independent stages of individual exocytotic secretion events. Biophys J 70:1061-1068.

Segura F, Brioso MA, Gomez JF, Machado JD, Borges R (2000) Automatic analysis for amperometrical recordings of exocytosis. J Neurosci Methods 103:151-156.

Sorensen JB, Nagy G, Varoqueaux F, Nehring RB, Brose N, Wilson MC,
Neher E (2003) Differential control of the releasable vesicle pools by SNAP-25 splice variants and SNAP-23. Cell 114:75-86.

Taupenot L, Harper KL, O'Connor DT (2003) The chromograninsecretogranin family. N Engl J Med 348:1134-1149.

Videen JS, Mezger MS, Chang YM, O'Connor DT (1992) Calcium and catecholamine interactions with adrenal chromogranins. Comparison of driving forces in binding and aggregation. J Biol Chem 267:3066-3073.

Wen G, Mahata SK, Cadman P, Mahata M, Ghosh S, Mahapatra NR, Rao F, Stridsberg M, Smith DW, Mahboubi P, Schork NJ, O'Connor DT, Hamilton BA (2004) Both rare and common polymorphisms contribute functional variation at CHGA, a regulator of catecholamine physiology. Am J Hum Genet 74:197-207.

Winkler H, Laslop A, Leitner B, Weiss C (1998) The secretory cocktail of adrenergic large dense-core vesicles: the functional role of the chromogranins. Adv Pharmacol 42:257-259. 